\title{
Evaluating comfort measures for commonly performed painful procedures in pediatric patients
}

This article was published in the following Dove Press journal: Journal of Pain Research

\author{
Sana Dastgheyb' \\ Keith Fishlock ${ }^{2}$ \\ Constantine Daskalakis' \\ Jami Kessel ${ }^{3}$ \\ Paul Rosen ${ }^{2}$ \\ 'Thomas Jefferson University, \\ Philadelphia, PA, ${ }^{2}$ Nemours Children's \\ Health System, Wilmington, DE, \\ ${ }^{3}$ Nationwide Children's Hospital \\ Columbus, $\mathrm{OH}$, USA
}

\begin{abstract}
Introduction: Management of pediatric pain from medical procedures is of great importance for improving both patient care and experience. In this study, we investigated methods of managing acute pain in infants and children by studying the correlation between the number of attempts to complete painful procedures, given different comfort measures.
\end{abstract}

Methods: The study is a retrospective review of 74,276 procedures performed at two pediatric hospitals in an integrated academic children's health system between 2013 and 2016. We compared three comfort measures most frequently offered: positions of comfort (POC), distraction (DIST), and pharmacological (PHARM). These methods were compared in the setting of four procedures: peripheral intravenous (PIV) catheter insertion, gastrointestinal tube placement, incision procedures, and bladder catheterization. We used the number of attempts needed to complete a procedure as a measure of efficacy minimizing distressing experience in an acutely painful setting (single attempt vs repeat attempts).

Results: Among younger children, DIST appears superior to the other two methods; it performs significantly better for three of the four procedures (PIV catheterization, incision wound, and urinary catheterization) among infants aged $<1$ year and for PIV catheterization among toddlers aged 1-3 years. For older children, POC tends to perform slightly better than the other two methods, although it is significantly better only for PIV catheterization among adolescents aged 13-21 years and urinary catheterization among children aged 9-12 years.

Conclusion: Results from this study may be used to determine appropriate comfort measures for painful procedures in pediatric setting.

Keywords: pediatric pain, pain management, comfort measures, acute pain, therapeutic

\section{Plain language summary}

More research is necessary to determine optimal methods of minimizing pain in children. This retrospective study determines which specific comfort measures are best suited for a single procedure. Result analyses are broken down by age cohort in order to determine possible suggestions for comfort measures in managing acute pain in clinical practice. Our study determined a set of comfort measures that can be used in specific age groups for each of four commonly performed painful procedures. If implemented, the use of appropriate comfort measures may significantly improve patient experience during commonly performed acutely painful procedures.

\section{Introduction}

Acute pain management in children is of great importance, and yet there is a paucity of research when it comes to determining which comfort measures may be best suited for commonly performed painful procedures. Research is further hindered by the

Tel +I 7035933917

Email ssd005@jefferson.edu 
subjectivity of pain and the absence of a suitable universal method to measure pain outcomes in children. ${ }^{1}$

The most commonly reported cause of pain in children in hospitals is procedural pain. ${ }^{2}$ Acutely painful procedures such as incision, needle-related, and tube-insertion procedures are performed by using common comfort measures, which may serve to either soothe or distract children and help them through painful procedures. Comfort measures can range from provider to provider and may depend on resources available to each child. These comfort measures, such as comforting positions, distraction techniques, and analgesia, are widely accepted as therapeutically useful in the management of pain and discomfort in children, yet no studies compare these comfort measures for children in the setting of acutely painful procedures. In addition, most measures of pain in children are qualitative or use Likert-type scales that ascribe quantitative values to qualitative data.

Many studies compare a handful of comfort measures for a single medical concern such as postoperative pain.,4 Other reports may focus on single treatments for a group of procedures, such as sweet tasting sucrose solutions for all needle-related procedures. ${ }^{5}$ The main method of assessing pain is through self-reported pain scales, self-reported experiences, or through provider observations, which have both benefits and limitations. These scales are inherently subjective and focus on outcomes such as facial expression diagrams for self-reporting and postural signs for provider reference. ${ }^{6,7}$ The benefit of such studies is that they are more closely related to pain, since pain is defined as a subjective experience. ${ }^{8}$ Although undeniably important, these studies do not report differences in efficacy of comfort measures using a quantifiable method but have been helpful in guiding the field of pediatric pain management. Currently, the consensus is that pain management in children should be multidisciplinary, using nonpharmacologic and pharmacologic methods to minimize pain so that procedures can be facilitated, thus making sure that the child does not feel undue psychological or physical trauma, either lasting or non-lasting. ${ }^{9}$

To our knowledge, there are no studies that use interval data to compare pain management in the setting of commonly performed procedures. In fact, pain management for routine procedures involves conventional, easily administered, and rapidly available therapeutics, which are regularly interchanged with no established guidelines or research-supported suggestions. While clinical intuition, which is the leading method of selecting comfort measures, may be effective in many cases, research using quantitative methods to detect possible quality improvement may be useful in procedural pain management.
This retrospective analysis of pain management techniques in children aimed to determine which comfort techniques may facilitate the completion of painful medical procedures without repeated attempts so that pain and anxiety for the patient and family may be minimized. The primary outcome for this study was "the number of attempts made in order to complete the procedure," which is not meant to directly connote less pain but is meant to correlate with factors such as decreased situational anxiety and procedural efficiency and is likely correlated with improved patient experience.

\section{Methods}

\section{Study design}

This study was evaluated and approved by the Nemours Institutional Review Board, was deemed a quality improvement study and therefore exempt from informed consent; however, our current report is meant to be a retrospective descriptive study that will lay the groundwork for quality improvement. De-identified data were extracted from a total of the 161,943 procedures performed at two academic pediatric hospitals within one children's health system between 2013 and 2016. These data comprise 52 clinics/units, 125 different procedures, and 785 different combinations of comfort measures. These data are filtered so that all procedures with missing information (eg, age not recorded) or implausible data (eg, 250 attempts at catheterization) are excluded. Consequently, 152,006 procedures remain for analyses. Of these, the top four procedures (in both female and male patients) comprise 117,480 procedures, which are further filtered to only those procedures fitting the appropriate comfort measure criterion discussed earlier. A complete breakdown of these procedures can be seen in Figure 1.

We analyzed three types of comfort techniques: positions of comfort (POC), distraction (DIST), and pharmacological (PHARM). We compared these comfort techniques across 1) four procedures: peripheral intravenous (PIV) catheter insertion, gastrointestinal (GI) tube placement, incision wound, and urinary catheterizations; and 2) five different age groups of children: infants ( $<1$ year), toddlers ( $1-3$ years of age), children aged $4-8$ years, children aged $9-12$ years, and adolescents $>12$ years of age. The choice of age groupings was guided by standard age groups for pediatric trials, outlined by Williams et al. ${ }^{10}$ The outcome of interest is a "successful event" which is defined in this study as a procedure performed in a single attempt. Comparisons of proportions of single attempts are therefore used in this study to determine which comfort measure is best suited for a given procedure. All other comfort measures are excluded. With these restrictions, the analyses are based on a total of 74,276 procedures (Figure 1). 


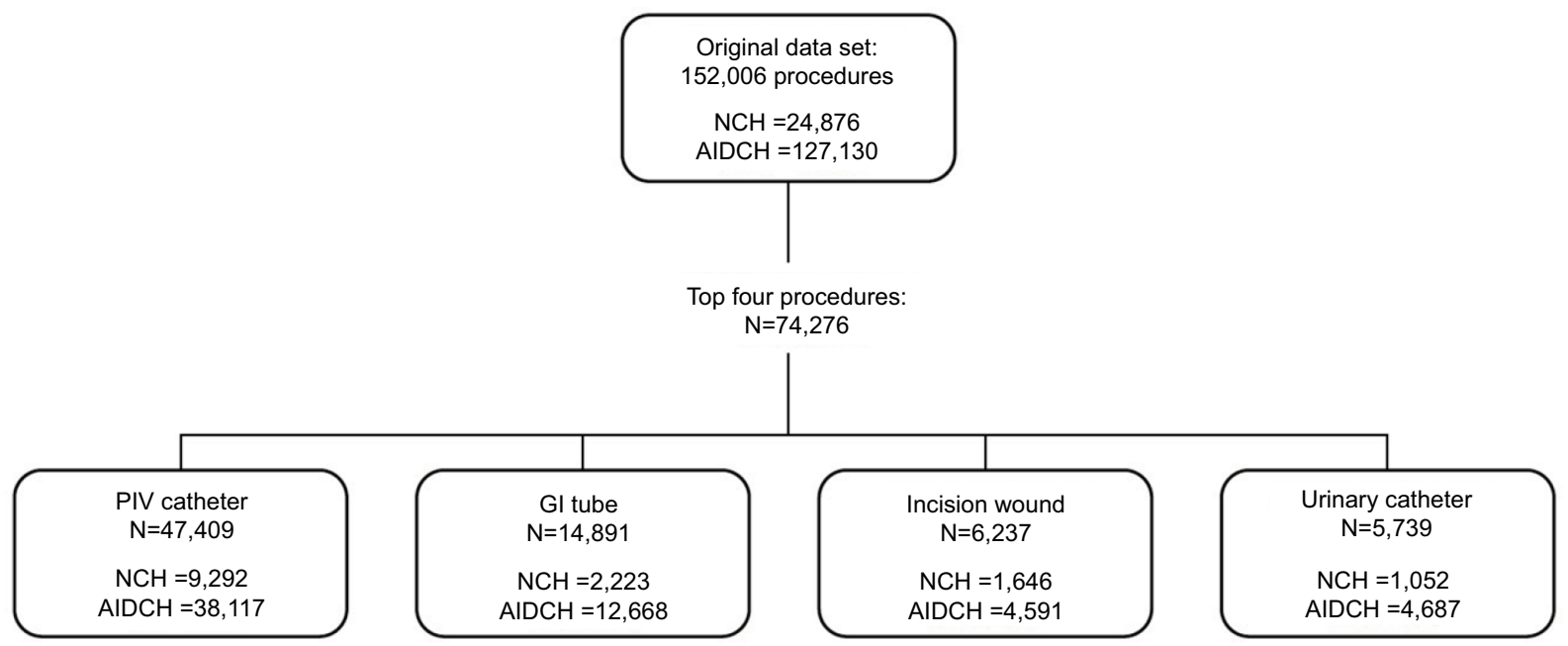

Figure I Outline of data categories.

Notes: Within each category, comfort measures are defined as position of comfort, distraction, or pharmacological. Breakdowns are shown in Table SI. Abbreviations: AIDCH, AI DuPont Children's Hospital; GI, gastrointestinal; NCH, Nemours Children's Hospital; PIV, peripheral intravenous.

\section{Comfort measures}

POC is strictly defined as the following: measures labeled as positions of comfort, caregiver comfort, swaddling alone, and relaxation. For the purpose of this study, no other comfort measures were included in this category. Relaxation in pediatric pain management is defined as a mind-body technique with deep breathing, laying in a comfortable position, ${ }^{11}$ and does not incorporate our parameters for the DIST group, which are specifically the distraction kit, pinwheels, or the iPad, not music, which was listed separately in our database and therefore excluded. Assignment to this category indicates that no distraction, pharmacological, or healing touch techniques were used in combination with the comfort measure. DIST comfort measures include play items, iPads, distraction kit, and bubbles or pinwheels to distract the patient from painful stimulus. Those children who were swaddled with DIST measures but had no pharmacological intervention in combination with DIST are included in this category. PHARM comfort measures include all patients who were listed as having received pharmacological intervention (eg, lidocaine or other analgesics) as a comfort measure but does not include children who received systemic anxiolysis medications. The PHARM category also excludes all children who received swaddling in combination with pharmacological comfort measures. Any children who received distraction with PHARM were excluded from this category.

\section{Procedures}

PIV catheter is defined as a peripheral intravenous line that is placed through the skin into a vein. The GI tube group can include any oral, nasal, or rectal placement of the tube into the GI tract. The incision group refers to the creation of any procedural incision. Urinary catheterization refers to the placement of a urinary tube into the bladder via the urethra.

\section{Data analysis}

The outcome of interest is a "successful event" defined as a procedure performed in a single attempt. Statistical analyses were performed by using GraphPad Prism version 5. Mean and standard deviations are recorded for each of the categories (Table S1). Chi-squared analyses are used to compare the three comfort measures within each type of procedure and age group. To determine significance, a global (two degrees of freedom) $p$-value is computed to determine if there are any differences across the three comfort measures and is then supplemented by three pairwise $p$-values.

\section{Recommendations}

Recommendations for a comfort measure given a particular procedure and age group of the child are made if:

1. The global $p$-value is $<0.05$

2. The recommended comfort measure is significantly better than the other two measures (ie, both pairwise $p$-values are $<0.05$ )

\section{Results}

The number of attempts for completion of a procedure ranges from 0 to 10 attempts in all procedures. The age of patients ranges from 0 to 21 years with $47.8 \%$ female and $52.2 \%$ male. 
The three comfort measures (ie, POC, DIST, and PHARM) are compared for each of the four procedures and each of the five age groups.

Table 1 presents a heat map of the percentage of "successful events" (ie, procedure performed in a single attempt) along with the corresponding global and pairwise $p$-values. Recommended comfort measures within each procedure type and age group are shown in bold.

The results are shown in Figure 2. As a general trend, the likelihood of a successful event (ie, a single attempt for a given procedure) increases with the child's age. Furthermore, different comfort measures work best for different procedures and ages of children. Table 2 presents a summary of the recommended comfort measures and is summarized below for each of the four procedure types.

\section{PIV catheterization}

In infants aged $<1$ year, DIST shows a significant advantage over both POC and PHARM (57\% vs 51\% and $48 \%$ successful events, respectively). Similarly, toddlers aged 1-3 years significantly benefit from DIST compared with POC and PHARM (73\% vs $66 \%$ and $65 \%$ successful events, respectively). Adolescents aged $\geq 13$ years benefit from $\mathrm{POC}$ compared with DIST and PHARM (75\% vs $73 \%$ and $68 \%$ successful events respectively) (Figure 2A).

\section{Incision wound}

In infants aged $<1$ year, DIST results in significantly more successful first attempts compared with POC and PHARM ( $55 \%$ vs $47 \%$ and $47 \%$ successful events, respectively) (Figure 2B).

\section{Gl tube insertion}

In toddlers aged 1-3 years, PHARM proves to be significantly more effective compared with DIST and POC (67\% vs 59\% and $57 \%$ successful events, respectively) (Figure 2C).

\section{Urinary catheter placement}

In infants aged $<1$ year, DIST is significantly better than both POC and PHARM (64\% vs 53\% and 52\% successful events, respectively). In children aged 9-12 years, POC is more likely to yield a successful first attempt over DIST and PHARM (82\% vs 66\% and 66\% successful events, respectively) (Figure 2D).

Table I Percentage of successful events (single attempts) with global and pairwise $p$-values

\begin{tabular}{|c|c|c|c|c|c|c|c|}
\hline & POC & DIST & PHARM & Global $p$-value & POC vs DIST & POC vs PHARM & DIST vs PHARM \\
\hline & \multicolumn{7}{|l|}{ <I year } \\
\hline PIV catheter & 51.43 & 57.22 & 48.28 & 0.001 & 0.001 & 0.022 & 0.001 \\
\hline Gl tube & 46.10 & 47.71 & 45.87 & 0.303 & 0.357 & 0.986 & 0.472 \\
\hline Incision wound & 47.44 & 54.93 & 47.44 & 0.003 & 0.005 & 0.999 & 0.044 \\
\hline \multirow[t]{2}{*}{ Urinary catheter } & 52.82 & 64.11 & 51.63 & 0.001 & 0.001 & 0.908 & 0.001 \\
\hline & \multicolumn{7}{|l|}{ I-3years } \\
\hline PIV catheter & 66.31 & 72.79 & 64.57 & 0.001 & 0.001 & 0.500 & 0.001 \\
\hline Gl tube & 57.34 & 58.59 & 67.32 & 0.010 & 0.897 & 0.015 & 0.030 \\
\hline Incision wound & 65.24 & 63.79 & 68.52 & 0.655 & 0.948 & 0.855 & 0.659 \\
\hline \multirow[t]{2}{*}{ Urinary catheter } & 60.41 & 69.57 & 65.00 & 0.045 & 0.047 & 0.698 & 0.628 \\
\hline & \multicolumn{7}{|l|}{$4-8$ years } \\
\hline PIV catheter & 77.17 & 77.39 & 75.76 & 0.431 & 0.990 & $0.74 I$ & 0.433 \\
\hline Gl tube & 77.07 & 70.02 & 64.81 & 0.083 & 0.240 & 0.092 & 0.576 \\
\hline Incision wound & 76.87 & 73.25 & 65.66 & 0.155 & 0.700 & 0.169 & 0.309 \\
\hline \multirow[t]{2}{*}{ Urinary catheter } & 78.38 & 65.98 & 68.00 & 0.060 & 0.062 & 0.284 & 0.949 \\
\hline & \multicolumn{7}{|l|}{$9-12$ years } \\
\hline PIV catheter & 77.15 & 76.80 & 72.05 & 0.004 & 0.981 & 0.067 & 0.005 \\
\hline Gl tube & 76.23 & 67.24 & 66.89 & 0.151 & 0.178 & 0.242 & 0.997 \\
\hline Incision wound & 73.33 & 74.40 & 74.36 & 0.968 & 0.969 & 0.983 & 0.999 \\
\hline \multirow[t]{2}{*}{ Urinary catheter } & 81.62 & 65.89 & 66.35 & 0.001 & 0.001 & 0.026 & 0.996 \\
\hline & \multicolumn{7}{|l|}{$13+$ years } \\
\hline PIV catheter & 75.37 & 73.13 & 67.62 & 0.001 & 0.103 & 0.001 & 0.001 \\
\hline Gl tube & 76.24 & 68.52 & 65.97 & 0.065 & 0.111 & 0.111 & 0.839 \\
\hline Incision wound & 77.66 & 71.21 & 68.33 & 0.030 & 0.053 & 0.119 & 0.805 \\
\hline Urinary catheter & 75.80 & 67.84 & & 0.001 & 0.051 & $0.5 \mathrm{II}$ & 0.003 \\
\hline
\end{tabular}

Scale: low high

Notes: With $45 \%$ being the lowest (red) and $81 \%$ being the highest (green), and the midpoint, 63 , being the yellow set point; the colors are a gradient to correlate directly with those numbers.

Abbreviations: DIST, distraction; GI, gastrointestinal; PHARM, pharmacological; PIV, peripheral intravenous; POC, positions of comfort. 

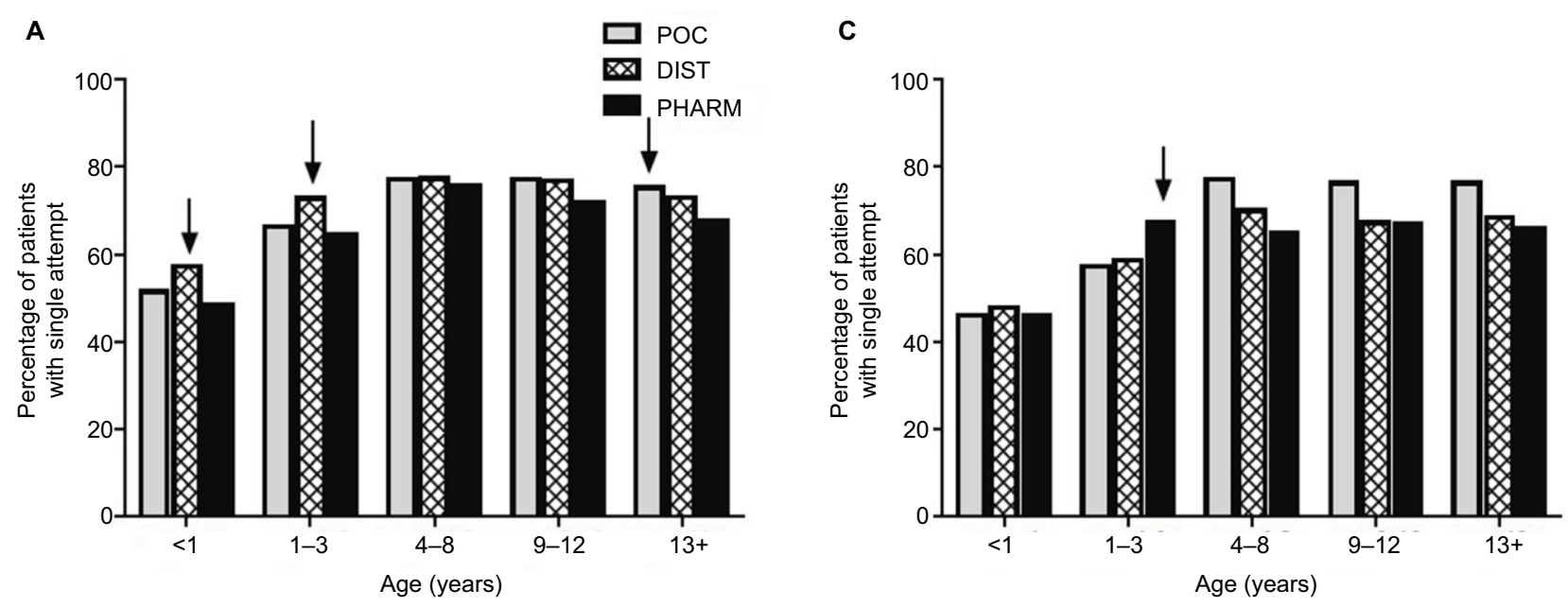

B

D
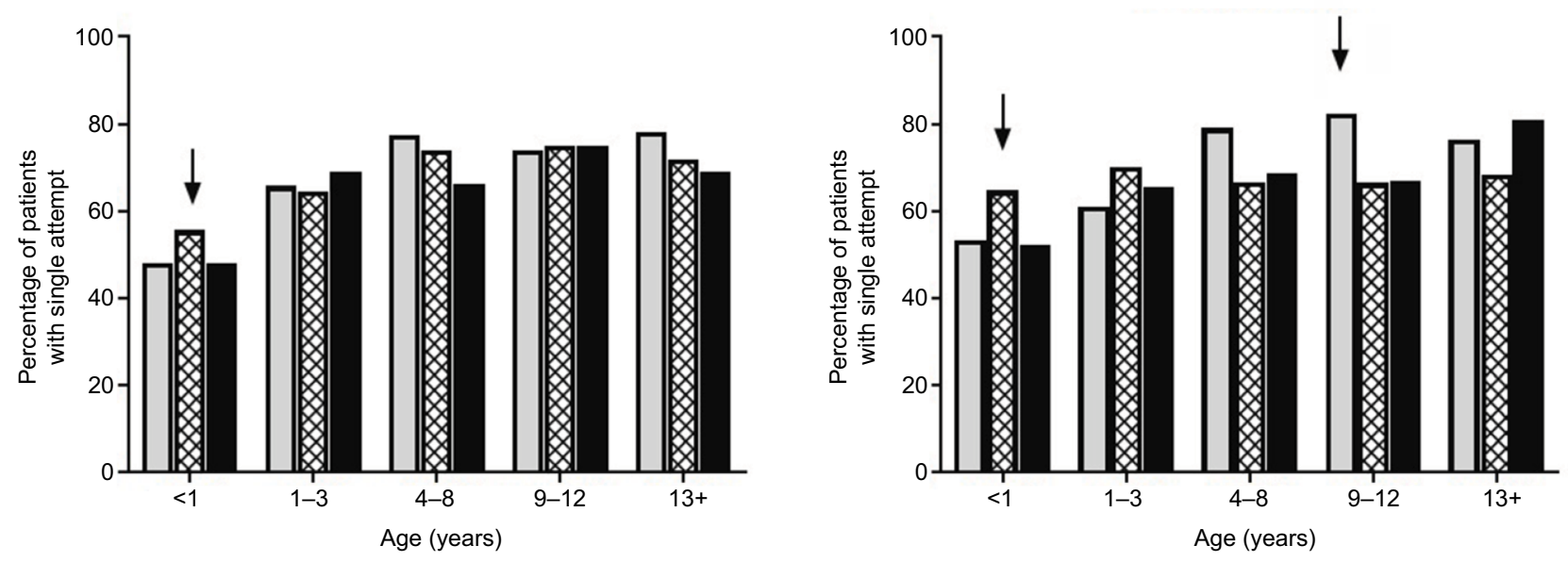

Figure 2 Percentage of successful events (single attempts) by comfort measure and age cohort.

Notes: (A) PIV catheterization, (B) incision wound, (C) Gl tube, (D) urinary catheter. Arrows indicate recommendations for comfort procedures.

Abbreviations: DIST, distraction; GI, gastrointestinal; PHARM, pharmacological; PIV, peripheral intravenous; POC, positions of comfort.

Table 2 Clinical recommendations for comfort measures

\begin{tabular}{lllll}
\hline & PIV catheter & GI tube & Incision wound & Urinary catheter \\
\hline Age $<$ l year & Distraction & No recommendation & Distraction & Distraction \\
Age I-3 years & Distraction & Pharmacy & No recommendation & (Distraction) \\
Age 4-8 years & No recommendation & No recommendation & No recommendation & No recommendation \\
Age 9-12 years & (Distraction) & No recommendation & No recommendation & Positions of comfort \\
Age 13+ years & Positions of comfort & No recommendation & Positions of comfort & (Pharmacy) \\
\hline
\end{tabular}

Notes: "( )" indicates a difference across the three comfort procedures, and the recommendation is based on a significant global p-value but only one significant pairwise $p$-value $(p<0.05)$.

Abbreviations: GI, gastrointestinal; PIV, peripheral intravenous.

\section{Discussion}

Due to the unique needs of each age group, we recommended that age be factored into the choice of comfort method. ${ }^{12}$ In some cases, suggested recommendations are made on the basis of a significant global $p$-value and one significant pairwise comparison. In many others, the data suggest no clearly superior method, and therefore, these are labeled "clinician choice" in Table 2.
As a general trend, the likelihood of a successful event (ie, a single attempt for a given procedure) can be seen to increase greatly as the age of the child increased. The average percentage of successful attempts ranges from $46 \%$ to $64 \%$ in the youngest age group, while in the oldest age group, successful attempts occurred between $66 \%$ and $81 \%$, including all procedures and comfort measures. These age effects may be reflective of the changes in biology and the differences 
in psychological development between the age groups. ${ }^{10} \mathrm{In}$ addition, DIST techniques appear to be more beneficial for younger children aged 0-3 years, as they prove to provide significantly greater chance of a successful procedure in all groups except the GI tube insertion group. POC appears to provide better comfort and therefore increased success rates for procedures performed in children aged $>4$ years, although it is significantly better only in two instances (ie, urinary catheter among children aged 9-12 years and PIV catheter among children aged $>13$ years).

For the PIV catheter group, DIST is the best method for both infants and toddlers. For children aged 9-12 years, DIST also appears to be the best comfort method; however, this is based on a significant global $p$-value with insignificant pairwise comparison. In the GI group, PHARM methods are most suited for toddlers aged 1-3 years. In the incision wound group, DIST provides the greatest benefits for infants aged $<1$ year. In the urinary catheter group, DIST significantly improves outcomes and is therefore recommended for infants and possibly also for toddlers. For children aged 9-12 years, POC is recommended, while for adolescents aged $\geq 13$ years, PHARM is recommended.

Overall, our study shows that younger age groups (ie, 0-3 years) appear to benefit from the use of distraction over pharmacy and positions of comfort. The efficacy of distraction in younger age groups has been supported by other studies using statistics based on subjective factors such as selfreported fear, rather than discrete objective measures. ${ }^{13-15}$ Our study also supports the finding from the Children's Hospital and Clinics of Minnesota which reported that pharmacological methods, while the most common in their hospital system, were not necessarily recommended for immediate procedural pain relief. ${ }^{16}$ In a Cochrane study review of children aged $<3$ years, researchers found that nonpharmacological methods show efficacy with neonates and that there is not sufficient evidence with older infants or young children. ${ }^{17}$ From this study, a trend can be seen that with increasing age cohorts, one single attempt in order to complete the procedure is recorded more frequently, indicating that choice of comfort measure may be more important in the younger age cohorts, particularly with infants and toddlers.

Interestingly, no single comfort measure proved to benefit children aged 4-8 years for any of the procedures in this study. This is supported by a study in children aged 4-12 years that assessed whether BUZZY, a distraction technique, decreased pain from needle insertion. The study showed that BUZZY does not lengthen the time of insertion compared to the other comfort measures. However, it did show that percep- tion of pain, as measured by the Wong-baker FACES pain rating scale, showed significantly decreased pain for catheter insertion with the use of BUZZY distraction. ${ }^{18}$

Our results indicated that as the age of children increases, the likelihood of benefits seen from distraction decreases and is replaced by positions of comfort or pharmaceutical comfort measures as techniques to increase the likelihood of a successful procedure. This is in contrast to a study at Boston Children's Hospital by Krauss et al that suggests physical comfort measures serve neonates and infants best, while distraction methods should be reserved for older children. ${ }^{19}$ The handbook of pediatric psychology, however, suggests that distraction is a critical component of pain management for children aged $\leq 4$ years. ${ }^{20}$

Due to the large sample size of our study, there are sufficient data to allow analyses to be conducted separately for different procedures and ages. "Number of attempts" is an important variable that encompasses the overall experience, the cost of service, and the efficacy of the procedure. The use of "number of attempts in order to complete the procedure" as a primary output for our study serves to provide a quantifiable and original method of assessing efficacy of minimizing distress associated with a painful procedure (not of decreasing pain itself). The main assumption with this readout is that with an ideal endpoint of one single attempt, labeled as a "successful event," procedures will be shorter and will correlate with decreased distress and anxiety for the patient. While this quantitative method can be seen as an advantage for this study, number of attempts is not a proxy for pain and does not measure actual pain.

Limiting elements such as practitioner skill, characteristics of the child, cognitive impairment status of the child, and the anxiety level of the child and family cannot be readily factored into these analyses, although they are known to be important factors in pain management. ${ }^{21-23}$ Our method does not assess combinations of therapies, which are commonly used, known to be highly effective, and are considered the recommended method by Friedrichdorf's "four non-negotiables for needle pain. ${ }^{24,25}$ In addition, procedures have been grouped in categories despite differences in technical difficulty and degrees of pain. One confounding factor in our results is that the varying characteristics of our subjects may account for the choice of comfort measure, which was not randomized, and therefore may have affected the primary outcome (number of attempts). Choice of comfort measure may also have been affected by the knowledge that comfort measures were to be recorded in the electronic medical record. Our study is also limited to a single health system 
and only reports outcomes for three comfort measures and four procedures and does not stratify further by child sex or other characteristics. Our results are further confounded by choice of comfort method by the clinician, which is not randomized, and are largely dependent upon the intuition of the health care professional and the temperament of the patient. Further deconstruction of methods, such as which tools of distraction from the distraction kit were used and which exact pharmacologic agents were used, are not reported in this study. Since our study reports the primary outcome of number of attempts, which cannot be assumed to be directly related to an outcome that is as subjective as pain, our results cannot be used to validate or invalidate studies that report on pain management techniques.

These results are from the use of three different comfort measures for acutely painful procedures in a single health system and require additional information from other hospital systems in order to further validate our findings. It is our hope that these recommendations may serve as a basis upon which to improve choice of comfort measures for children undergoing acutely painful procedures. If implemented, these changes in practice may increase the likelihood of successfully completing painful procedures with fewer attempts, thereby saving time, resources, and also sparing the child from psychological stress.

\section{Disclosure}

The authors report no conflicts of interest in this work.

\section{References}

1. Howard RF. Current status of pain management in children. JAMA. 2003;290(18):2464.

2. Shomaker K, Dutton S, Mark M. Pain prevalence and treatment patterns in a US children's hospital. Hosp Pediatr. 2015;5(7):363-370.

3. Berde CB, Lehn BM, Yee JD, Sethna NF, Russo D. Patient-controlled analgesia in children and adolescents: a randomized, prospective comparison with intramuscular administration of morphine for postoperative analgesia. J Pediatrics. 1991;118(3):460-466.

4. Wood CE, Goresky GV, Klassen KA, Kuwahara B, Neil SG. Complications of continuous epidural infusions for postoperative analgesia in children. Can J Anaesth. 1994;41(7):613-620.

5. Harrison D, Yamada J, Adams-Webber T, Ohlsson A, Beyene J, Stevens B. Sweet tasting solutions for reduction of needle-related procedural pain in children aged one to 16 years [review]. Cochrane Database Syst Rev. 2015;5:CD008408.
6. von Baeyer CL, Spagrud LJ. Systematic review of observational (behavioral) measures of pain for children and adolescents aged 3 to 18 years. Pain. 2007;127(1-2):140-150.

7. Tomlinson D, von Baeyer CL, Stinson JN, Sung L. A systematic review of faces scales for the self-report of pain intensity in children. Pediatrics. 2010;126(5):e1168-e1198.

8. McGrath PJ, Stevens BJ, Walker SM, Zempsky WT. Oxford Textbook of Paediatric Pain. https://books.google.com/books?vid=9780199642656. Accessed May 23, 2017.

9. Cramton REM, Gruchala NE. Managing procedural pain in pediatric patients. Curr Opin Pediatr. 2012;24(4):530-538.

10. Williams K, Thomson D, Seto I, et al. Standard 6: age groups for pediatric trials. Pediatrics. 2012;129(Suppl 3):153-160.

11. Lin YC, Lee ACC, Kemper KJ, Berde CB. Use of complementary and alternative medicine in pediatric pain management service: a survey. Pain Med. 2005;6(6):452-458.

12. Mazur A, Radziewicz Winnicki I, Szczepański T. Pain management in children. Ann Agric Environ Med. 2013;1(1):28-34.

13. Broome ME, Lillis PP, McGahee TW, Bates T. The use of distraction and imagery with children during painful procedures. Oncol Nurs Forum. 1992;19(3):499-502.

14. Koller D, Goldman RD. Distraction techniques for children undergoing procedures: a critical review of pediatric research. J Pediatr Nurs. 2012;27(6):652-681.

15. Windich-Biermeier A, Sjoberg I, Dale JC, Eshelman D, Guzzetta CE. Effects of distraction on pain, fear, and distress during venous port access and venipuncture in children and adolescents with cancer. J Pediatr Oncol Nurs. 2007;24(1):8-19.

16. Friedrichsdorf SJ, Postier A, Eull D, et al. Pain outcomes in a us children's hospital: a prospective cross-sectional survey. Hosp Pediatr. 2015;5(1):18-26.

17. Uman LS, Chambers CT, McGrath PJ, Kisely S. A systematic review of randomized controlled trials examining psychological interventions for needle-related procedural pain and distress in children and adolescents: an abbreviated cochrane review. J Pediatr Psychol. 2008;33(8):842-854.

18. Moadad N, Kozman K, Shahine R, Ohanian S, Badr LK. Distraction using the buzzy for children during an IV insertion. J Pediatr Nurs. 2016;31(1):64-72.

19. Krauss BS, Calligaris L, Green SM, Barbi E. Current concepts in management of pain in children in the emergency department. Lancet. 2016;387(10013):83-92.

20. Blount RL, Zempsky WT, Jaaniste T, Evans S, Cohen LL, Devine KA. Management of Pediatric Pain and Distress due to Medical Procedures. 4th ed. New York: Guilford Press;2009.

21. Pederson C, Bjerke T. Pediatric pain management: a research-based clinical pathway. Dimens Crit Care Nurs. 1998;18(3):42-51.

22. Rush SL, Harr J. Evidence-based pediatric nursing: does it have to hurt? AACN Adv Crit Care. 2001;12(4):597-605.

23. Ljusegren G, Johansson I, Gimbler Berglund I, Enskär K. Nurses' experiences of caring for children in pain. Child Care Health Dev. 2012;38(4):464-470.

24. Riddell RP, Racine N, Turcotte K, et al. Nonpharmacological management of procedural pain in infants and young children: an abridged cochrane review. Pain Res Manag. 2011;16(5):321-330.

25. Friedrichsdorf SJ. Four steps to eliminate or reduce pain in children caused by needles (part 1). Pain Manag. 2017;7(2):89-94. 


\section{Supplementary material}

Table SI Procedure and age group analysis with mean and standard deviations

\begin{tabular}{|c|c|c|c|c|c|c|c|c|c|}
\hline & \multicolumn{3}{|c|}{ Positions of comfort (POC) } & \multicolumn{3}{|c|}{ Distraction } & \multicolumn{3}{|c|}{ Pharmacological } \\
\hline & $\bar{n}$ & Mean & SD & $\mathbf{n}$ & Mean & SD & $\bar{n}$ & Mean & SD \\
\hline \multicolumn{10}{|l|}{$<1$ year } \\
\hline PIV catheter & 8233 & 1.8 & I.I & 4504 & 1.6 & 0.9 & 2494 & 1.9 & 1.2 \\
\hline Gl tube & 6226 & 1.9 & 1.2 & 2882 & 1.9 & 1.2 & 1792 & 2.0 & 1.5 \\
\hline Incision wound & 1248 & 1.8 & 1.0 & 781 & 1.7 & 1.0 & 430 & 1.9 & I.I \\
\hline Urinary catheter & 1136 & 1.7 & 0.9 & 716 & 1.5 & 0.8 & 490 & 1.7 & 1.0 \\
\hline \multicolumn{10}{|l|}{$1-3$ years } \\
\hline PIV catheter & 2223 & 1.4 & 0.7 & 3895 & 1.3 & 0.7 & 1976 & 1.5 & 0.8 \\
\hline Gl tube & 593 & 1.6 & 0.8 & 768 & 1.6 & 0.9 & 306 & 1.6 & 1.0 \\
\hline Incision wound & 164 & 1.4 & 0.6 & 406 & 1.5 & 0.9 & 108 & 1.5 & 1.0 \\
\hline Urinary catheter & 245 & 1.5 & 0.8 & 483 & 1.4 & 0.6 & 120 & 1.4 & 0.7 \\
\hline \multicolumn{10}{|l|}{$4-8$ years } \\
\hline PIV catheter & 876 & 1.3 & 0.6 & 4843 & 1.3 & 0.6 & 1448 & 1.3 & 0.6 \\
\hline Gl tube & 157 & 1.4 & 0.8 & 447 & 1.4 & I.I & 108 & 1.4 & 0.6 \\
\hline Incision wound & 134 & 1.3 & 0.6 & 486 & 1.3 & 0.6 & 99 & 1.4 & 0.6 \\
\hline Urinary catheter & III & 1.3 & 0.7 & 244 & 1.4 & 0.7 & 75 & 1.3 & 0.5 \\
\hline \multicolumn{10}{|l|}{$9-12$ years } \\
\hline PIV catheter & 639 & 1.3 & 0.5 & 4082 & 1.3 & 0.6 & 1066 & 1.3 & 0.6 \\
\hline Gl tube & 122 & 1.3 & 0.5 & 348 & 1.4 & 0.6 & 148 & 1.4 & 0.5 \\
\hline Incision wound & 135 & 1.3 & 0.6 & 539 & 1.3 & 0.6 & 117 & 1.4 & I.I \\
\hline Urinary catheter & 136 & 1.2 & 0.5 & 730 & 1.4 & 0.6 & 104 & 1.4 & 0.6 \\
\hline \multicolumn{10}{|l|}{$13+$ years } \\
\hline PIV catheter & 2302 & 1.3 & 0.6 & 7571 & 1.3 & 0.6 & 1257 & 1.4 & 0.7 \\
\hline Gl tube & 202 & 1.3 & 0.6 & 648 & 1.4 & 0.6 & 144 & 1.4 & 0.6 \\
\hline Incision wound & 376 & 1.3 & 0.6 & 1094 & 1.4 & 0.8 & 120 & 1.4 & 0.7 \\
\hline Urinary catheter & 281 & 1.3 & 0.6 & 656 & 1.4 & 0.7 & 212 & 1.3 & 0.6 \\
\hline
\end{tabular}

Abbreviations: $\mathrm{Gl}$, gastrointestinal; PIV, peripheral intravenous; SD, standard deviation.

\section{Publish your work in this journal}

The Journal of Pain Research is an international, peer reviewed, open access, online journal that welcomes laboratory and clinical findings in the fields of pain research and the prevention and management of pain. Original research, reviews, symposium reports, hypothesis formation and commentaries are all considered for publication.

\section{Dovepress}

The manuscript management system is completely online and includes a very quick and fair peer-review system, which is all easy to use. Visit http://www.dovepress.com/testimonials.php to read real quotes from published authors. 